\title{
Summarizing primary and secondary effects
}

Karlson, Kristian Bernt

Published in:

Research in Social Stratification and Mobility

DOI:

10.1016/j.rssm.2013.01.001

Publication date:

2013

Document version

Peer reviewed version

Document license:

Unspecified

Citation for published version (APA):

Karlson, K. B. (2013). Summarizing primary and secondary effects. Research in Social Stratification and Mobility, 33, 72-82. https://doi.org/10.1016/j.rssm.2013.01.001 


\title{
Summarizing primary and secondary effects
}

\author{
THIS PAPER IS PUBLISHED IN \\ RESEARCH IN SOCIAL STRATIFICATION AND MOBILITY, 2013 \\ VOL. 33, 72-82 \\ Link: http://www.sciencedirect.com/science/article/pii/S0276562413000024
}

This is a post-print (i.e. final draft post-refereeing) version according to SHERPA/ROMEO

Kristian Bernt Karlson

SFI - The Danish National Center for Social Research Herlufs Trolle Gade 11

DK-1052 Copenhagen K, Denmark

Department of Education, Aarhus University, Tuborgvej 164,

DK-2400 Copenhagen NV, Denmark

Email: kbk@dpu.dk.

Draft: January 19th, 2013

5,616 words (including all text, notes, and references)

1 appendix

5 tables

Running head: Primary and secondary effects

Keywords: primary effects, secondary effects, inequality of educational opportunity, educational inequality, decomposition, logit, logistic regression

Acknowledgements: I thank Richard Breen for his constructive comments and for lending me the data for the analyses. I also thank Anders Holm for his many suggestions which have significantly improved the paper. 


\title{
Summarizing primary and secondary effects
}

\begin{abstract}
Current methods for decomposing class differentials in educational decisions into primary and secondary effects produce many parameters, rendering them ill-equipped for parsimonious comparisons across countries or birth cohorts. This paper develops a parametric method that provides an optimal summary of primary and secondary effects across discrete class origins. Under the testable assumption that the pattern of effects of class origins on academic ability is proportional to the pattern of effects of class origins on educational choice net of academic ability, the method returns a single summary measure. Applying the method to two cohorts born in the UK in 1958 and 1970 suggests that-even with increasing overall inequality of educational opportunity - the contribution of secondary effects to class differentials in A-level completion has remained constant between the two cohorts.
\end{abstract}

Keywords: primary effects; secondary effects; decomposition; logit; logistic 


\section{Summarizing primary and secondary effects}

\section{Introduction}

Educational stratification researchers have become increasingly occupied with decomposing social class differentials in educational decisions into primary and secondary effects. In this context, primary effects refer to the indirect effect of social class on the educational decision that results from class differences in academic ability or performance, while secondary effects refer to the direct effect of social class on the educational decision holding academic ability constant. Following Boudon (1974), current research gives theoretical interpretation to these two effects: Whereas primary effects are a result of class differences in genetic and socio-cultural dispositions, secondary effects stem from class differences in the expected returns to completing a certain educational level. Higher class students need to attain a relatively higher level of schooling than lower class students, if they are to avoid downward mobility and enter the same or higher social class as their parents (Breen \& Goldthorpe, 1997).

While the theoretical interpretations of primary and secondary effects have been spelled out rather convincingly, stratification researchers continue to discuss how best to identify and quantify primary and secondary effects in empirical analyses. One strand of research directly estimates the theoretical parameters governing the model of relative risk aversion by Breen and Goldthorpe (1997) (Becker, 2003; Becker \& Hecken, 2009; Breen \& Yaish, 2006; Gabay-Egozi, Shavit, \& Yaish, 2010; Holm \& Jæger, 2008; Jacob \& Weiss, 2011; Jæger \& Holm, 2012; Need \& de Jong, 2001; Stocké, 2007; van de Werfhorst \& Hofstede, 2007), while another strand indirectly infers the relative importance of secondary effects over primary effects from observed correlations between social class, educational 
decisions, and academic ability or performance (Becker, 2009; Boado, 2011; Contini \& Scagni, 2011; Davies, Heinesen, \& Holm, 2002; Erikson, 2007; Erikson et al., 2005; Erikson \& Rudolphi, 2010; Jackson, 2010, 2013; Jackson et al., 2007; Kloosterman et al., 2009; Karlson \& Holm, 2011; Neugebauer, 2010; Neugebauer \& Schindler, 2012; Schindler \& Lörz, 2012; Schindler \& Reimer, 2010). In analyses using discrete measures of social class, this latter strand of research is characterized by producing a plethora of parameters, complicating comparisons across birth cohorts or countries or both. Because comparative studies lie at the heart of stratification research, this situation is unfortunate and warrants and acceptable solution.

This paper offers a solution to this issue. It presents a method for summarizing the relative contributions of primary and secondary effects to class differentials in educational choices across discrete measures of social class. Drawing on work by Breen and Karlson (2012), I use a parametric approach that—under a testable proportionally assumptionprovides a single, yet optimal, summary. The method is based on regression models with parametrically weighted predictor variables; a strategy that has a long tradition in stratification research and social science research more generally (Yamaguchi, 2002). For example, one type of model is the unidiff or log-multiplicative layer-effect model (Erikson \& Goldthorpe, 1992; Xie, 1992), another is the stereotyped ordered regression of Anderson (1984), and a third is the diagonal reference model of Sobel (1981). The approach I suggest deviates from these models in that it places a cross-equation proportionality constraint on the social class effects on both academic ability and the educational decision net of academic ability. I apply the method to the case of trends in the primary and secondary effects in Alevel completion for cohorts born 1958 and 1970 in the UK. The analysis shows thatdespite increase in overall class inequalities in A-level completion-secondary effects have 
been constant between the two birth cohorts, accounting for approximately two-thirds of the class differentials.

\section{Existing methods and their limitations}

The literature on primary and secondary effects provides several ways of decomposing class differentials in discrete educational choices (Erikson et al., 2005; Buis, 2010; Karlson \& Holm, 2011; Morgan, 2012). One limitation pertaining to all of these methods is that, whenever discrete measures of social class are employed, they produce a plethora of parameters. This issue arises because each contrast between classes is assigned a primary and a secondary effect. In analyses involving $\mathbf{J}$ social classes, the total number of contrasts is $1 / 2 J(J-1)$. In analyses involving five origin classes, this amounts to 10 contrasts and consequently 10 primary and secondary effects. Seven class analyses would return 21 primary and secondary effects. If researchers are interested in particular class contrasts, then such detailed information may prove valuable. But in cross-country and cross-cohort analyses—-so central to the stratification discipline-researchers often prefer optimal summaries of results as the basis for comparisons (Breen \& Karlson, 2012).

The literature on decompositions of primary and secondary effects has suggested two ways of solving the issue of having too much information. The first is to collapse social classes into a few, large classes (e.g., Jackson et al., 2007). This strategy is useful whenever collapsing classes does not ignore important heterogeneity within the larger classes. While the validity of collapsing classes in principle can be tested, it is far from clear how researchers should proceed if collapsing classes ignores important information. The second approach takes a simple average of decomposition percentages over class contrasts (e.g., Karlson \& Holm, 2011). While this approach allows for many contrasts, it does not assign proper weights to each of the decomposition percentages. Moreover, in their application of 
this approach, Karlson and Holm (2011) took the average over only a subset of all class contrasts, ignoring potential heterogeneity in the remaining contrasts.

A further issue relating to the abundance of parameters arises in the method by Erikson et al. (2005) (also see, Jackson et al., 2007). The method produces two sets of primary and secondary effect estimates, introducing indeterminacy in how best to report the results (Buis, 2010). Jackson et al. (2007) suggest reporting the simple average of the two. Whether this approach can be considered optimal is yet to be explored.

In sum, existing methods for decomposing primary and secondary effects produce much information, and no common approach for optimally summarizing this information has been developed. To develop such an approach, I draw on the recent work by Breen and Karlson (2012), who suggests a general method for summarizing the extent to which education mediates social mobility. To provide optimal summaries, they suggest combining the decomposition method of Karlson, Holm, and Breen (2012) and Breen, Karlson, and Holm (Forthcoming) with using parametrically weighted predictor variables, i.e., applying proportionality constraints to vectors of class coefficients. In what follows I extend this method to primary and secondary effects decompositions.

\section{Summarizing primary and secondary effects}

\subsection{The method by Karlson, Holm, and Breen}

I first briefly explain the method by Karlson, Holm, and Breen (2012), as this is developed in Breen, Karlson, and Holm (Forthcoming) and Karlson and Holm (2011). Let $y^{*}$ be a continuous latent propensity to complete a certain educational level. Let $x$ be a discrete measure of social class with $j=1,2, \ldots, \mathrm{J}$ classes, where $j=1$ is a reference category, and let $z$ be a continuous measure of academic ability. I first regress $x$ and $z$ on $y^{*}$,

$$
y^{*}=\alpha+\sum_{j=2}^{J} \beta_{j} x_{j}+\gamma z+e
$$


and then regress $x$ on $z$,

$$
z=\mu+\sum_{j=2}^{J} \theta_{j} x_{j}+v
$$

where $e$ and $v$ are independent error terms. $\beta_{j}$ is the $j$ th direct effect of social class on the educational propensity net of academic ability (with each effect being interpreted relative to the reference category), $\gamma$ is the direct effect of academic ability on the educational propensity net of social class, and $\theta_{j}$ is the $j$ th unconditional effect of social class on academic ability. In terms of primary and secondary effects, $\beta_{j}$ is the secondary effect and $\gamma \theta_{j}$ is the primary effect for class $j$, with $\beta_{j}+\gamma \theta_{j}$ being the total class differential in the educational propensity for class $j$ (relative to class $j=1$ ) (Karlson \& Holm, 2011).

However, because $y^{*}$ is latent, $\beta_{j}$ and $\gamma$ are not identified. Now assume that we observe a binary manifestation of $y^{*}, y$, such that

$$
\begin{aligned}
& y=1 \text { if } y^{*}>0 \\
& y=0 \text { if otherwise. }
\end{aligned}
$$

If we place a distributional assumption on the error term, $e$, in (1), then we can derive the logistic response model. Rewrite the error term in (1), $e=\sigma \omega$, where $\omega$ is assumed to be a standard logistic random variable, with mean zero and variance $\pi^{2} / 3$, and $\sigma$ is a scale parameter, allowing the standard deviation of the error to differ from that of the standardized logistic distribution (Cramer, 2003). Under this assumption, write the logistic response model corresponding to the latent linear model in (1) as

$$
\operatorname{logit}(y=1)=a+\sum_{j=2}^{J} b_{j} x_{j}+c z
$$

where $a=\frac{\alpha}{\sigma}, \sum_{j=2}^{J} b_{j}=\sum_{j=2}^{J} \frac{\beta_{j}}{\sigma}$, and $c=\frac{\gamma}{\sigma}$ (see Karlson, Holm, \& Breen, 2012). In other words, using the logistic model in (4), we can identify the underlying regression coefficients 
up to scale, with the scale parameter being a simple function of the latent error variance in $(1)$.

As noted by Karlson and Holm (2011), the scale identification of the logistic regression coefficients means that the direct and indirect (via academic ability) effects of social class on the educational propensity are also identified up to scale. In this context, for class $j$ (relative to class $j=1$ ), $b_{j}=\frac{\beta_{j}}{\sigma}$ is the direct effect, $c \theta_{j}=\frac{\gamma \theta_{j}}{\sigma}$ is the indirect effect, and $b_{j}+c \theta_{j}=\frac{\beta_{j}+\gamma \theta_{j}}{\sigma}$ is the total class differential. Yet, the fraction of the total class differential that is a result of the indirect effect through academic ability,

$$
\frac{c \theta_{j}}{b_{j}+c \theta_{j}}=\frac{\gamma \theta_{j}}{\beta_{j}+\gamma \theta_{j}},
$$

is a scale-free measure, and so is the fraction that is a result of the direct effect,

$$
1-\frac{c \theta_{j}}{b_{j}+c \theta_{j}}=\frac{\beta_{j}}{\beta_{j}+\gamma \theta_{j}} .
$$

In primary and secondary effect decompositions, (5a) is the primary effect, while (5b) is the secondary effect.

In passing I notice that giving indirect and direct effects the theoretical interpretation of primary and secondary effects rests on an assumption not tested here. Primary effects are rooted in socio-cultural differences between classes and find their expression in unequal academic abilities, while secondary effects are rooted in the fear of social demotion that leads to class differentials in the returns to a given level of education. Yet, the fear of social demotion might also lead parents to invest in their offspring's abilities, as hypothesized in human capital theories of the family (Becker \& Tomes, 1986). When this is the case, primary effects are overstated in decompositions as the one stated in (5). Thus, the decomposition in (5) only identifies the relative contribution of primary and secondary effects to the class 
differential in an educational decision under the assumption that the fear of social demotion does not lead families to rationally invest in their offspring's academic abilities.

\subsection{Applying proportional constraints}

Following a well-established tradition in sociological methodology (Yamaguchi, 2002), in a recent paper Breen and Karlson (2012) suggest placing proportionality constraints on parametrically weighted predictor variables to provide optimal summaries of the mediating role of education in social mobility. Here I extend their ideas to the case of primary and secondary effects. The idea is to place a proportionality constraint on the vectors of social class coefficients in Equations (4) and (2), assuming that the pattern of direct class effects on the educational decision (net of academic ability) in (4) is proportional to the pattern of class effects on academic ability in (2).

The method I develop is best understood in terms sheaf coefficients (Heise, 1972; Whitt, 1986). A sheaf coefficient is a parametrically weighted block of predictor variables, yielding a single coefficient for the block of variables. With nominal variables, such as social class, the sheaf coefficient thus provides a single class coefficient in which the contribution of each class variable is optimally weighted to explain the outcome variable of interest. ${ }^{1}$ This property also means that the sheaf coefficient does not depend on the choice of reference dummy for nominal variables (Heise, 1972), i.e., the method yields identical results irrespective of chosen reference social class.

The sheaf coefficient can be considered the effect of a latent variable with no measurement error. In the context of the approach I develop here, this latent variable is defined as

\footnotetext{
${ }^{1}$ The expression "optimally weighted" should be understood in the regression sense of the word, as a linear combination maximizing the explanatory power of the model (Yamaguchi 2002).
} 


$$
\eta=\sum_{j=2}^{J} \lambda_{j} x_{j}
$$

where $\lambda_{j}$ is the weight for class $j$. Replacing the latent variable in (6) with the class dummies in (1) and (2) gives

$$
\begin{aligned}
& y^{*}=\kappa+\varphi_{1} \eta+\pi z+u=\kappa+\varphi_{1} \sum_{j=2}^{J} \lambda_{j} x_{j}+\pi z+u \\
& z=\psi+\varphi_{2} \eta+w=\psi+\varphi_{2} \sum_{j=2}^{J} \lambda_{j} x_{j}+w
\end{aligned}
$$

where $\varphi_{1}$ is the effect of the latent social class variable on the educational propensity and $\varphi_{2}$ is the corresponding effect on academic ability. Because the latent variable in (6), $\eta$, enters both (7) and (8), the system of equations assume that the vector of class coefficients in (7) is proportional to the vector of class coefficients in (8).

To identify the parameters for the decomposition, we need to make two assumptions. First, to derive the logistic counterpart to (7), we assume that $y$ is a binary manifestation $y^{*}$ as in (3), and that $u$ is logistically distributed such that $u=\omega \sigma$, where $\omega$ is standard logistic random variable and $\sigma$ is a scale parameter. ${ }^{2}$ This yields

$$
\operatorname{logit}(y=1)=k+\phi_{1} \sum_{j=2}^{J} \lambda_{j} x_{j}+p z
$$

where $k=\frac{\kappa}{\sigma}, \phi_{1}=\frac{\varphi_{1}}{\sigma}$, and $p=\frac{\pi}{\sigma}$

Second, to identify the system of equations in (8) and (9), I place a constraint on $\varphi_{2}$ in (8), with $\varphi_{2}=1$. This choice of constraint is arbitrary, because I could have constrained other parameters, or because I could have chosen another value for $\varphi_{2}$. Yet, $\varphi_{2}=1$ is a convenient

\footnotetext{
${ }^{2}$ This scale parameter will differ from the scale parameter in the model in (1), but I use the same letter, $\sigma$, for ease of exposition.
} 
choice for the approach I suggest here, because it simplifies the expressions for the direct and indirect effects.

The system of equations in (8) and (9) can be estimated using maximum likelihood in which both equations are estimated simultaneously under the proportionality constraint. The Appendix provides the maximum likelihood program, implemented in $\operatorname{Stata}^{\circledR}$ version 12 , which I use in the empirical analyses in a later section. The full Stata ${ }^{\odot}$ dofile generating my results can be accessed through the journal's website.

While the first assumption — that of the logistic error term—cannot be tested, the proportionality constraint, $\varphi_{2}=1$, can. The constrain can be tested with a simple likelihood ratio (LR) test that evaluates the difference in log likelihoods between the constrained model and an unconstrained model relative to the difference in degrees of freedom. The unconstrained model is a model in which no constraints are placed on the vector of social class coefficients, i.e., the logit equation and the linear equation each have their own class coefficient vector.

The LR test is informative about the extent to which providing a single summary measure is meaningful. Whenever the LR test does not reject the null hypothesis of no difference in model fits, the constraint holds and the summary measure provides a useful summary of primary and secondary effects. In contrast, whenever the LR test does reject the null, the constraint does not hold and it is difficult to provide a meaningful summary. The researcher should consequently inquire into the reasons for this lack of proportionality and evaluate whether the proportionality assumption appears overly restrictive. Because the likelihood ratio test depends on sample size, in analyses involving large data sets, researchers will often reject the null of no difference in model fits. In these situations, researchers should carefully inspect the coefficient vectors in the unconstrained model to evaluate the reasonableness of the assumption. If the assumption appears implausible, then researchers 
should consider specifying less restrictive models with fewer constraints. Such type of models would allow for, say, two-dimensional effects of the social class variable across the equations, much similar to the logic of model selection in the stereotyped ordered regression of Anderson (1984). However, while this strategy points to a more general class of models, it loses parsimony and I do not develop it further in this paper.

Under the two assumptions - the logit assumption and the parameter constraint-it is possible to derive an optimal summary of the relative contributions of primary and secondary effects to class differentials in educational decisions. Applying the decomposition rules in Breen, Karlson, and Holm (2012), I obtain the following decomposition:

$$
\begin{array}{ll}
\text { Direct effect: } & \phi_{1}=\frac{\varphi_{1}}{\sigma} \\
\text { Indirect effect: } & p \varphi_{2}=p=\frac{\pi}{\sigma} \\
\text { Total effect: } & \phi p+p \varphi_{2}=\frac{\varphi_{1}+\pi}{\sigma},
\end{array}
$$

where the first equalities in (10b) and (10c) hold given the constraint $\varphi_{2}=1$. Consequently, I can derive the fraction of the total effect that is a result of the indirect effect, i.e., the primary effect, as

$$
\frac{p}{\phi_{1}+p}=\frac{\pi}{\varphi_{1}+\pi}
$$

and the fraction owing to the direct effect, i.e., the secondary effect, as

$$
1-\frac{p}{\phi_{1}+p}=\frac{\varphi_{1}}{\varphi_{1}+\pi}
$$

The fractions in (11) are both scale-free measures, meaning that they are useful for comparative purposes. 


\section{Application}

\subsection{Data}

To illustrate the use of summary measure, I analyze data from two cohorts born in 1958 and 1970 in the UK. I apply the methods to the data set used in Breen and Goldthorpe (2001). ${ }^{3}$ The data set for the 1958 cohort is the National Child Development Study, and for the 1970 cohort the British Cohort Study. I restrict my sample to students with valid information on all variables, returning 3,566 respondents for the 1958 cohort and 3,970 respondents for the 1970 cohort. I refer to Breen and Goldthorpe (2001) for a detailed description of the data.

I use whether (1) or not (0) the student completed his or her A-levels as my binary outcome variable. ${ }^{4}$ This information was tapped at age 23 for the 1958 cohort and at age 26 for the 1970 cohort. The fraction of a cohort completing A-levels increased slightly across the two surveys; 37.1 percent in the 1958 cohort and 39.0 percent in the 1970 cohort. For my measure of father's social class, I use a seven class version of the EGP schema (Erikson \& Goldthorpe, 1992):

I Upper service

II Lower service

III Routine nonmanual

IV Petty bourgeoisie

V Supervisors etc.

VI Skilled manual

VII Nonskilled manual

\footnotetext{
${ }^{3}$ I thank Richard Breen for kindly sharing the data.

${ }^{4}$ I use Breen and Goldthorpe's coding (2001) of the educational attainment variable into the National Vocational Qualification (NVQ) classification. The variable consists of six levels, ranging from no qualification to higher degree. I collapse NVQ levels 0-2 for respondents not completing A-levels and 3-5 for students who complete A-levels.
} 
The father's class information was tapped at ages 11 and 10 in the 1958 and 1970 cohort, respectively; that is, in 1969 and 1980. As Table 1 shows, the class distribution of fathers changed across that decade: The fraction placed in the service class increased from 27 percent for the 1958 cohort to 39 percent for the 1970 cohort. Similarly, the fraction in unskilled manual occupations decreased from 19 percent to 11 percent.

\section{-- TABLE 1 HERE --}

I measure academic performance with the cognitive ability tests used in Breen and Goldthorpe (2001). For the 1958 cohort, a general ability test was administered at age 11. For the 1970 cohort, a very similar ability test was administered at age 10 . Both variables are standardized to have mean zero and unit variance in each cohort. Finally, I include gender as a control covariate in all models, thereby controlling all decompositions for the potentially confounding influence of this variable.

\subsection{Results using the method by Karlson, Holm, and Breen}

Table 2 reports for each class contrast in each cohort the percentage of the class differential in A-level completion that is a result of secondary effects, using the method in Karlson and Holm (2011). ${ }^{5}$ Ignoring the outlier in class contrast VI and V, the overall pattern for the 1958 cohort suggests that secondary effects dominate primary effects, and I find a very similar pattern for the 1970 cohort. The two cohorts however differ in the percentage level in roughly half of the class contrasts. For example, for contrast II and III, the role of secondary effects has declined dramatically between the cohorts, from 83.4 percent to 1.1 , suggesting that primary effects explain most of this class differential in 1970 cohort. Other examples of such differences between cohorts can be considered, but in this analysis I simply emphasize that significant cohort variation exists in the magnitudes of secondary effects.

\footnotetext{
${ }^{5}$ Results calculated with Stata $^{\odot}$ ado file, $k h b$, by Kohler, Karlson, and Holm (2011).
} 


\subsection{Results using the summary measure}

The question however arises whether secondary effects have come to play a more important role, overall, in generating class differentials in A-level completion across the two cohorts. While the detailed and disaggregated information in Table 2 provides an entry to studying such changes, it is not immediately clear how to summarize the results for each cohort in an optimal way from the percentages in the table. Using a simple average of secondary effects percentages, as suggested in Karlson and Holm (2011), would, for example, be highly misleading, because of the outlier in class contrast VI and V in the 1958 cohort. While many alternative summaries could be constructed, I here report the results based on the joint model involving the latent social class variable $(\eta)$, as defined in Equations (6), (8), and (9). The model is estimated using maximum likelihood. The Appendix shows the program, and the full Stata ${ }^{\odot}$ dofile generating the results can be accessed through the journal's website.

Table 3, which shows the model results for each cohort, is divided into four parts. Firstly I report the coefficients for the logit equation predicting A-level completion [Equation (9)], secondly the linear model predicting the academic ability variable [Equation (8)], thirdly the latent variable equation with social class dummies predicting the latent social class variable [Equation (6)], and fourthly model summary statistics.

\section{-- TABLE 3 HERE --}

For the 1958 cohort, the effect of the latent variable in the A-level equation-that is, the proportionality factor-is $\varphi_{1}=1.257$, suggesting that the vector of social class coefficients is roughly 25 percent larger in this equation than in the academic ability equation. In other words, $\varphi_{1}=1.257$ represents the overall relative deviation from the effect of the latent social class variable, constrained to $\varphi_{2}=1$, in the academic ability equation. 
However, in the final row of Table 3 I report the p-value of the likelihood ratio test, comparing the constrained model in Table 3 with an unconstrained model. The unconstrained model is a model in which the A-level and ability equations each have their own vector of social class coefficients. The p-value is 0.044 , indicating that the constrained model has a significantly poorer fit to the data and, consequently, the parametric constraint is not wellsupported by the data. In other words, a parsimonious summary of primary and secondary effects cannot readily be given for the 1958 cohort. To inquire into this issue, Table 4 reports the vector of social class coefficients for the unconstrained models. An informal evaluation of the coefficients for the 1958 cohort suggests that the proportionality assumption is violated for classes III and V. Nonetheless, because the ordering of social class effects is quite similar across the two equations, keeping the proportionality constraint does not appear overly restrictive, and so, in this example, I keep this constraint in order for me to compare primary and secondary effects between the two cohorts.

\section{-- TABLE 4 HERE --}

For the 1970 cohort, I find a pattern of results which is similar to the 1958 cohort. However, the magnitudes of coefficients for the logit equation predicting A-level completion cannot be compared, since these coefficients are measured on scales that differ in unidentifiable ways (Allison, 1999). Yet, one important difference between the two cohorts is that the constrained model in the 1970 cohort fits the data as well as the unconstrained model. The likelihood ratio test returns a p-value of 0.359 , suggesting that for this cohort a parsimonious summary of primary and secondary effects can be given.

Despite the lack of model fit for the 1958 cohort, in Table 5 I report the summary decomposition of class differentials in A-level completion using the constrained models in Table 3. While the direct, indirect, and total effects cannot be compared across cohorts (given their cohort-specific scales), the relative contributions of primary and secondary effects can. 
Using the decomposition in Equation (11), I find that the fraction of the total class differential that is a result of secondary effects is highly similar between the two cohorts; 61.2 and 62.8 percent for the 1958 and 1970 cohort, respectively.

\section{-- TABLE 5 HERE --}

In sum, the role played by the fear of social demotion in the generation of class differentials in A-level completion dominates and has changed little between the 1958 and 1970 cohorts. To better understand this result in the context of overall class inequality in Alevel completion, the final column of Table 5 reports McKelvey and Zavoina's (1975) Rsquared from a logit model regressing the A-level dummy on the social class dummies. ${ }^{6}$ This measure has been suggested as a general, scale-invariant measure of inequality of educational opportunity, suitable for comparative stratification research (Breen, Holm, \& Karlson, 2012). For the 1958 cohort, the R-squared is 7.3 percent, indicating that of the total variance in the propensity to complete A-levels, social class explains 7.3 percent. However, for the 1970 cohort, the R-squared has almost doubled to 13.5 percent, suggesting that social class has become a stronger predictor of A-level completion between the two cohorts. In this context of increasing inequality of educational opportunity, stable primary and secondary effects point to that the relative importance of the two mechanisms generating class inequalities in acquiring A-level credentials has remained unchanged.

\section{Conclusion}

This paper presents a solution to the problem that current methods for decomposing class differentials in educational decisions produce a plethora parameters. It develops a simple approach using parametrically weighted predictor variables to obtain a single, yet optimal,

\footnotetext{
${ }^{6}$ This is calculated using user-written command, $n l c o r r$, for Stata ${ }^{\circledR}$ version 12.
} 
summary measure of primary and secondary effects. The summary measure is useful in research aiming at making parsimonious comparisons of primary and secondary effects across layers such as countries or cohorts. Yet, while the method is advantageous for this type of research, its assumption of proportionality also presents researchers with challenges in situations when the assumption does not hold. In these situations, researchers need to carefully inspect the data to understand why the assumption is violated and whether it can be considered consequential for the results. Future research needs to consider both the methodological and substantive consequences of marked violations of the proportionality assumption for comparative studies of the role of primary and secondary effects in the generation of class inequalities in educational attainment. 


\section{References}

Allison, P.D. (1999). Comparing Logit and Probit Coefficients Across Groups. Sociological Methods \& Research, 28, 186-208.

Anderson, J.A. (1984). Regression and Ordered Categorical Variables. Journal of the Royal Statistical Society Series A, 46, 1-30.

Becker, G.S. \& Tomes, N. (1986). Human Capital and the Rise and Fall of Families. Journal of Labor Economics, 4, 1-47.

Becker, R. (2003). Educational Expansion and Persistent Inequalities of Education: Utilizing Subjective Expected Utility Theory to Explain Increasing Participation Rates in Upper Secondary School in the Federal Republic of Germany. European Sociological Review, 19, 124.

Becker, R. (2009). Wie können "bildungsferne" Gruppen für ein Hochschulstudium gewonnen werden? Köllner Zeitschrift für Soziologie und Sozialpsychologie, 61, 563-593.

Becker, R. \& Hecken, A.E. (2009). Higher Education or Vocational Training? An Empirical Test of the Rational Action Model of Educational Choices Suggested by Breen and Goldthorpe and Esser. Acta Sociologica, 52, 25-45.

Boado, H.C. (2011). Primary and secondary effects in the explanation of disadvantage in education: the children of immigrant families in France. British Journal of Sociology of Education, 32, 407-430.

Boudon, R. (1974). Education, Opportunity and Social Inequality. New York: Wiley.

Breen, R. \& Goldthorpe, J. (1997). Explaining Educational Differentials: Towards a Formal Rational Action Theory. Rationality and Society, 9, 275-305.

Breen, R. \& Goldthorpe, J. (2001). Class, Mobility, and Merit: The Experience of Two British Cohorts. European Sociological Review, 17, 81-101.

Breen, R. \& Karlson, K.B. (2012). Education and Social Mobility: New Analytical Approaches. Unpublished manuscript.

Breen, R., Karlson, K.B., \& Holm, A. (Forthcoming). Total, Direct, and Indirect effects in Logit and Probit Models. Sociological Methods and Research.

Breen, R., Holm, A., \& Karlson, K.B. (2012). Correlations and Non-Linear Probability Models. Unpublished manuscript.

Breen, R. \& Yaish, M. (2006). Testing the Breen-Goldthorpe model of educational decision making. Pp. 232-258 in Morgan, S.L., Grusky, D.B., \& Fields, G.B. (Eds.): Mobility and Inequality: Frontiers of Research in Sociology and Economics. Stanford, California: Stanford University Press. 
Buis, M. (2010). Direct and indirect effects in a logit model. The Stata Journal, 10, 11-29.

Contini, D. \& Scagni, A. (2011). Secondary School Choice in Italy: Ability or Social Background? Pp. 223-245 in Attanasio, M. \& Capursi, V. (Eds.): Statistical Methods for the Evaluation of University Systems. Heidelberg: Springer.

Cramer, J.S. (2003). Logit Models. From Economics and Other Fields. Cambridge: Cambridge University Press.

Davies, R., Heinesen, E., \& Holm, A. (2002). The relative risk aversion hypothesis of educational choice. Journal of Population Economics, 15, 683-713.

Erikson, R. (2007). Social selection in Stockholm schools: primary and secondary effects on the transition to upper secondary education. In: Scherer, S., Pollak, R., Otte, G., Gangl, M. (eds.): From Origin to Destination: Trends and Mechanisms in Social Stratification Research. Chicago: The University of Chicago Press.

Erikson, R. \& Goldthorpe, J.H. (1992). The Constant Flux: A Study of Class Mobility in Industrial Societies. Clarendon Press, Oxford.

Erikson, R., Goldthorpe, J. H., Jackson, M., Yaish, M., \& Cox, D.R. (2005). On class differentials in educational attainment. Proceedings of the National Academy of Science (PNAS) of the USA, 102, 9730-9733.

Erikson, R. \& Rudolphi, F. (2010). Change in Social Selection to Upper Secondary SchoolPrimary and Secondary Effects in Sweden. European Sociological Review, 26, 291-305.

Gabay-Egozi, L., Shavit, Y., \& Yaish, M. (2010). Curricular Choice: A Test of a Rational Choice Model of Education. European Sociological Review, 26, 447-463.

Heise, David R. (1972). Employing Nominal Variables, Induced Variables, and Block Variables in Path Analysis. Sociological Methods and Research, 1, 147-173.

Holm, A. \& Jæger, M. M. (2008). Does Relative Risk Aversion explain educational inequality? A dynamic choice approach, Research social stratification and mobility, 26, 199219.

Jackson, M. (2010). Investigating Inequalities in Educational Attainment. Pp. 163-177 in Stillwell, J., Norman, P., Thomas, C., \& Surridge, P. (Eds.): Spatial and Social Disparities: Understanding Population Trends and Processes: volume 2. Dordrecht: Springer.

Jackson, M. (Ed.) (2013). Determined to Succeed? Performance versus Choice in Educational Attainment. Stanford: Stanford University Press.

Jackson, M., Erikson, R., Goldthorpe, J.H., \& Yaish, M. (2007). Primary and Secondary Effects in Class Differentials in Educational Attainment: The Transition to A-Level Courses in England and Wales. Acta Sociologica, 50, 211-229.

Jacob, M. \& Weiss, F. (2011). Class origin and young adults' re-enrollment. Research in Social Stratification and Mobility, 29, 415-426. 
Jæger, M.M. \& Holm, A. 2012. Conformists or rebels? Relative risk aversion, educational decisions and social class reproduction. Rationality and Society, 24, 221-253.

Karlson, K.B., Holm, A., \& Breen, R. (2012). Comparing Regression Coefficients Between Models using Logit and Probit: A New Method. Sociological Methodology, 42, 286-313.

Karlson, K.B. \& Holm, A. (2011). Decomposing primary and secondary effects: A new method. Research in Social Stratification and Mobility, 29, 221-237.

Kloosterman, R., Ruiter, S., De Graaf, P.M., \& Kraaykamp, G. (2009). Parental education, children's performance and the transition to higher secondary education: trends in primary and secondary effects over five Dutch school cohorts (1965-99). The British Journal of Sociology, 60, 377-398.

Kohler, U., Karlson, K.B., \& Holm, A. (2011). Comparing coefficients of nested nonlinear probability models. The Stata Journal, 11, 420-438.

McKelvey, R.D. \& Zavoina, W. (1975). A Statistical Model for the Analysis of Ordinal Level Dependent Variables. Journal of Mathematical Sociology, 4, 103-120.

Morgan, S.L. (2012). Models of College Entry in the United States and the Challenges of Estimating Primary and Secondary Effects. Sociological Methods \& Research, 41, 17-56.

Need, A. \& de Jong, U. (2001). Educational differentials in the Netherlands: Testing Rational Action Theory. Rationality and Society, 13, 71-98.

Neugebauer, M. (2010). Bildungsungleichheit und Grundschulempfehlung beim Übergang auf das Gymnasium: Eine Dekomposition primärer und sekundärer Herkunftseffekte. Zeitschrift für Soziologie, 39, 202-214.

Neugebauer, M. \& Schindler, S. (2012). Early transitions and tertiary enrolment: The cumulative impact of primary and secondary effects on entering university in Germany. Acta Sociologica, 55, 19-205.

Schindler, S. \& Lörz, M. (2012). Mechanisms of Social Inequality Development: Primary and Secondary Effects in the Transition to Tertiary Education Between 1976 and 2005. European Sociological Review, 28, 647-660.

Schindler, S. \& Reimer, D. (2010). Primäre und sekundäre Effekte der sozialen Herkunft beim Übergang in die Hochschulbildung. Köllner Zeitschrift für Soziologie und Sozialpsychologie, 62, 623-653.

Sobel, M.E. (2008). Diagonal Mobility Models: A Substantively Motivated Class of Designs for the Analysis of Mobility Effects. American Sociological Review, 46, 893-906.

Stocké, V. (2007). Explaining Educational Decisions and Effects of Families' Social Class Position: An Empirical Test of the Breen-Goldthorpe Model of Educational Attainment. European Sociological Review, 23, 505-519. 
van de Werfhorst, H. \& Hofstede, S. (2007). Cultural capital or relative risk aversion? Two mechanisms for educational inequality compared. The British Journal of Sociology, 58, 391415.

Whitt, H.P. (1986). The Sheaf Coefficient: A Simplified and Expanded Approach. Social Science Research, 15, 174-189.

Yamaguchi, K. (2002). Regression Models With Parametrically Weighted Explanatory Variables. Sociological Methodology, 32, 219-245. 


\section{Appendix}

Stata code for $\mathrm{ml}$ program implementing the constrained model.

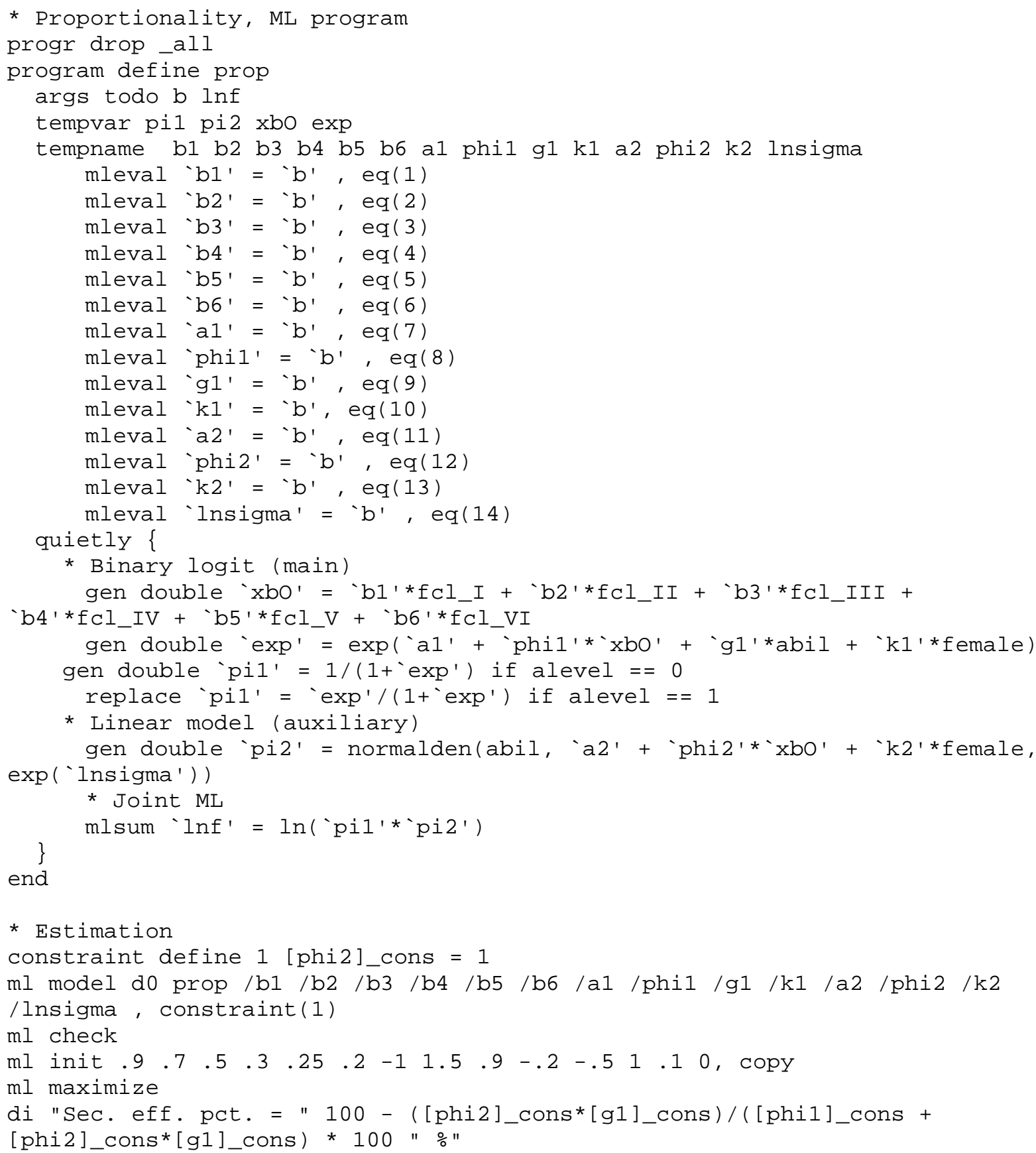

Stata code for ml program implementing the unconstrained model, for likelihood ratio test.

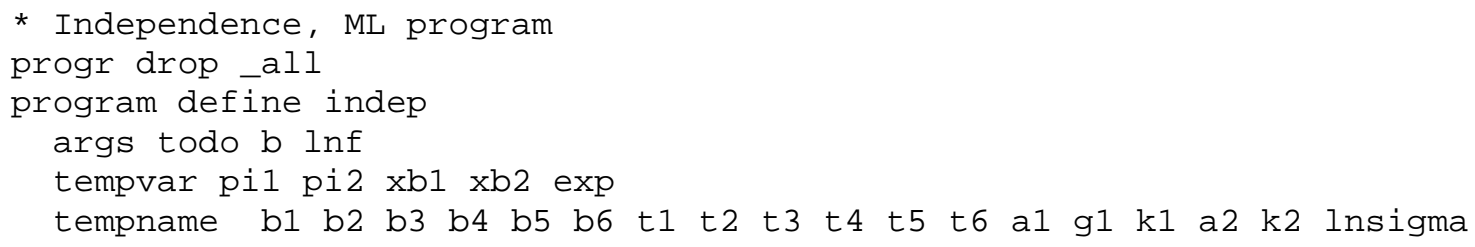




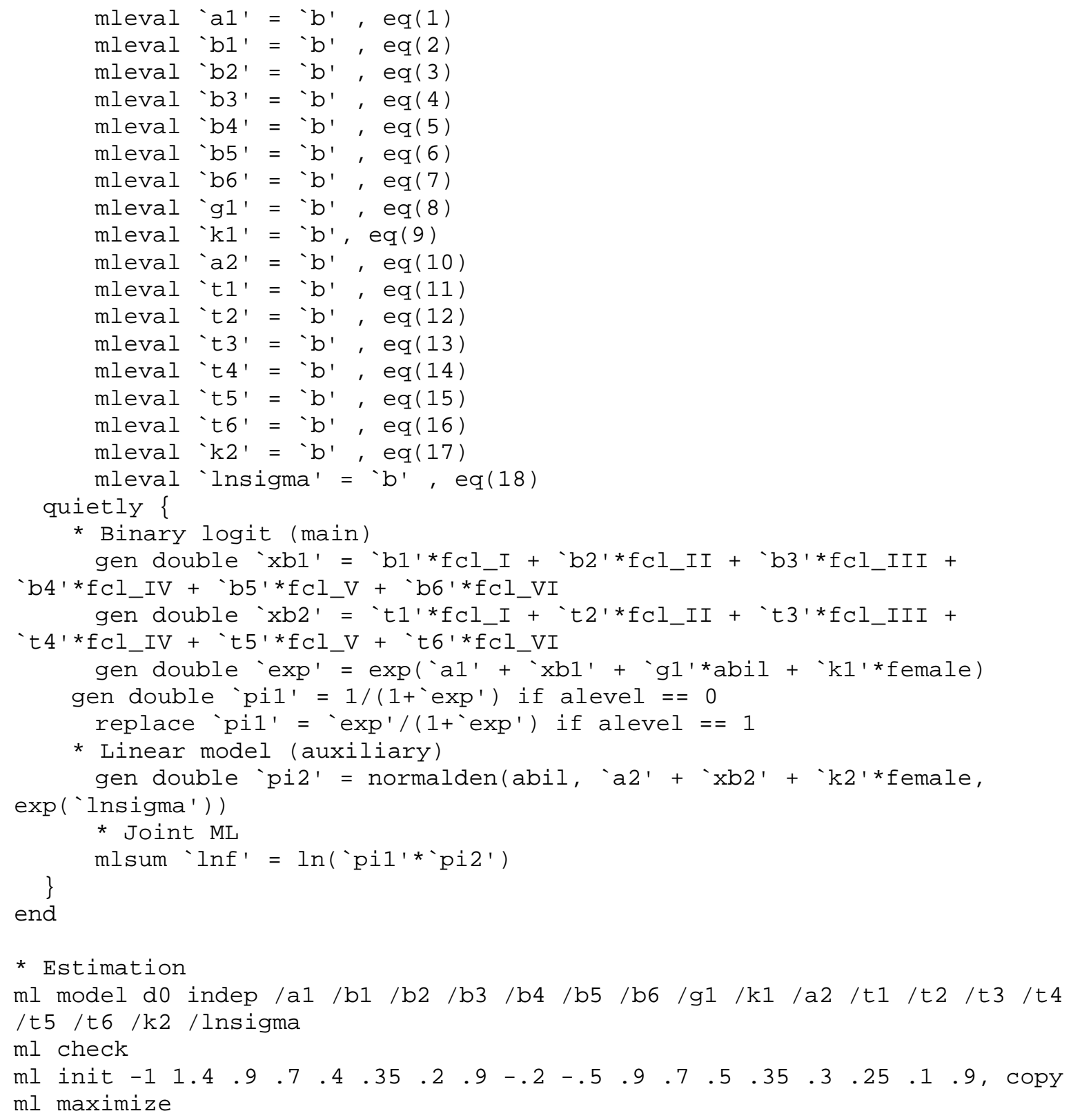




\section{TABLES}

TABLE 1. Distributions of father's class for children born in 1958 and 1970. Occupational information tapped in 1969 and 1980, respectively. Percent.

\begin{tabular}{lrr}
\cline { 2 - 3 } I Upper service & 9.03 & 17.86 \\
II Lower service & 17.86 & 20.83 \\
III Routine nonman. & 10.26 & 6.42 \\
IV Petty bourg. & 5.66 & 10.18 \\
V Supervisors etc. & 6.48 & 10.15 \\
VI Skilled manual & 32.02 & 23.48 \\
VII Nonskilled manual & 18.68 & 11.08 \\
Total & 100.00 & 100.00 \\
\hline
\end{tabular}


TABLE 2. Secondary effect percentages with gender as control covariate. Percent.

\begin{tabular}{lcccccr}
\hline & \multicolumn{7}{c}{$\mathbf{1 9 5 8}$} & & & & \\
\hline & & II & III & IV & V & VI \\
\cline { 2 - 7 } I Upper service & & & & & & \\
II Lower service & 72.1 & & & & & \\
III Routine nonman. & 76.9 & 83.4 & & & & \\
IV Petty bourg. & 69.8 & 67.3 & 19.4 & & & \\
V Supervisors etc. & 73.9 & 75.1 & 65.4 & 95.1 & & \\
VI Skilled manual & 62.6 & 55.5 & 22.4 & 24.4 & 2669.3 & \\
VII Nonskilled manual & 64.5 & 61.1 & 50.3 & 56.3 & 39.7 & 69.3 \\
\hline & & $\mathbf{1 9 7 0}$ & & & & \\
\hline & II & III & IV & V & VI & \\
I Upper service & & & & & & \\
II Lower service & 73.9 & & & & & \\
III Routine nonman. & 54.2 & 1.1 & & & & \\
IV Petty bourg. & 66.6 & 61.7 & 82.0 & & & \\
V Supervisors etc. & 62.2 & 55.0 & 70.8 & -9.4 & & \\
VI Skilled manual & 65.0 & 60.8 & 73.1 & 59.2 & 78.2 & \\
VII Nonskilled manual & 62.1 & 57.4 & 67.2 & 51.3 & 62.0 & 34.0 \\
\hline
\end{tabular}


TABLE 3. Joint model with proportionality constraints. Coefficients and standard errors.

\begin{tabular}{|c|c|c|c|c|}
\hline & \multicolumn{2}{|c|}{1958} & \multicolumn{2}{|c|}{1970} \\
\hline & $\mathrm{b}$ & $\mathrm{SE}$ & $\mathrm{b}$ & SE \\
\hline \multicolumn{5}{|l|}{ A-level (logit) } \\
\hline Latent social class variable $\left(\varphi_{1}\right)$ & 1.257 & 0.156 & 1.773 & 0.155 \\
\hline Academic ability $(p)$ & 0.797 & 0.044 & 1.052 & 0.047 \\
\hline Female (ref. Male) & -0.563 & 0.078 & 0.260 & 0.076 \\
\hline Intercept & -0.300 & 0.131 & -1.428 & 0.097 \\
\hline \multicolumn{5}{|l|}{ Academic ability (linear) } \\
\hline Latent social class variable $\left(\varphi_{2}\right)$ & 1 & - & 1 & - \\
\hline Female (ref. Male) & 0.271 & 0.032 & -0.084 & 0.030 \\
\hline Intercept & -0.510 & 0.037 & -0.353 & 0.044 \\
\hline \multicolumn{5}{|l|}{ Latent social class variable $(\eta)$} \\
\hline I Upper service & 0.936 & 0.061 & 0.854 & 0.054 \\
\hline II Lower service & 0.685 & 0.050 & 0.643 & 0.051 \\
\hline III Routine nonman. & 0.542 & 0.057 & 0.493 & 0.062 \\
\hline IV Petty bourg. & 0.418 & 0.068 & 0.289 & 0.055 \\
\hline V Supervisors etc. & 0.368 & 0.065 & 0.216 & 0.055 \\
\hline VI Skilled manual & 0.238 & 0.042 & 0.109 & 0.047 \\
\hline VII Nonskilled manual (ref.) & - & - & - & - \\
\hline \multicolumn{5}{|l|}{ Model summary } \\
\hline$-2 * \log \mathrm{L}$ & \multicolumn{2}{|c|}{$13,828.30$} & \multicolumn{2}{|c|}{$15,089.42$} \\
\hline $\begin{array}{l}\text { p-value (test constrained } \\
\text { vs. unconstrained model) }\end{array}$ & \multicolumn{2}{|c|}{0.044} & \multicolumn{2}{|c|}{0.359} \\
\hline
\end{tabular}

Note: All coefficients are significant on a five percent level. 
TABLE 4. Vector of social class coefficients in unconstrained models. Logit and metric coefficients.

I Upper service

II Lower service

\begin{tabular}{rrrr}
\multicolumn{2}{c}{1958} & \multicolumn{2}{c}{1970} \\
\hline $\begin{array}{r}\text { A-level } \\
\text { (Logit) }\end{array}$ & $\begin{array}{r}\text { Ability } \\
\text { (Linear) }\end{array}$ & $\begin{array}{r}\text { A-level } \\
\text { (Logit) }\end{array}$ & $\begin{array}{r}\text { Ability } \\
\text { (Linear) }\end{array}$ \\
\hline 1.314 & 0.902 & 1.483 & 0.856 \\
0.861 & 0.684 & 0.979 & 0.688 \\
0.479 & 0.590 & 0.977 & 0.451 \\
0.450 & 0.436 & 0.359 & 0.322 \\
0.223 & 0.421 & 0.369 & 0.214 \\
0.393 & 0.217 & 0.074 & 0.136 \\
- & - & - & -
\end{tabular}


TABLE 5. Summary of primary and secondary effects under the proportionality assumption. Inequality of educational opportunity (IEO) is measured using the McKelvey and Zavoina's $\mathrm{R}^{2}$ from a binary logit regression of A-level completion on the social class dummies. Estimates and standard errors.

\begin{tabular}{lcccc}
\hline & \multicolumn{2}{c}{1958} & \multicolumn{2}{c}{1970} \\
\cline { 2 - 5 } Direct effect $\left(\varphi_{1}\right)$ & Est. & SE & Est. & SE \\
Indirect effect $\left(p \varphi_{1}\right)$ & 0.797 & 0.042 & 1.052 & 0.050 \\
Total effect $\left(\varphi_{1}+p \varphi_{1}\right)$ & 2.054 & 0.160 & 2.825 & 0.166 \\
Secondary effect, $\%$ & 61.19 & 3.390 & 62.76 & 2.477 \\
IEO, $\mathrm{R}^{2}, \%$ & 7.32 & 0.977 & 13.54 & 1.138 \\
\hline
\end{tabular}

Note: All standard errors calculated using the bootstrap, with 1,000 replications. Estimates of IEO in A-level completion in the 1958 and 1970 cohorts are statistically significantly different at a 0.001 significance level. 